\title{
P373: Contamination and cross contamination on hospital surfaces (near touch site)
}

\author{
D Lary ${ }^{1 *}$, K Hardie $^{1}$, J Randle ${ }^{2}$ \\ From 2nd International Conference on Prevention and Infection Control (ICPIC 2013) \\ Geneva, Switzerland. 25-28 June 2013
}

\section{Introduction}

The hospital cleaning and it is link to healthcare associated infection is an on-going debate. There has been little evidence that environment cleaning is important in reducing spread of infection compared to other known risks. While a clean environment is usually taken for granted there is little evidence to show that cleanliness could be an important controlling factor in the spread of infection.

\section{Objectives}

Investigate the contamination of environmental surfaces (near touch sites) and whether this plays a role in the transmission of HCAI and multi-drug resistant organisms and examine the role of cleaning in reducing the number of pathogens.

\section{Methods}

Pathogens present on near touch sites were identified using molecular techniques and the role of cleaning surfaces was assessed by determining the total number of colony forming unit directly before and after cleaning, 2, 4 , and 6 hour later. Antibiotic susceptibility profiling was applied to isolated bacteria and the genetic profiles of the isolates were evaluated using randomly amplified polymorphic DNA (RAPD) and the spasequence-based typing methodfor discriminating between $S$. aureus isolates to evaluate the average linkage within samples.

\section{Results}

Significant differences between surface contamination before and after cleaning $(\mathrm{P}<0.001)$ was observed. Similarly, the repopulation of bacteria ontouch surfaces was significantly lower just after cleaning and started to increase by time. A total of 509 near patient touch site swab samples were obtained, $21 \%$ were S. aureus, $14 \%$ E. faecalis and $11 \%$ P. aeruginosa. Samples collected showed resistance to commonly used clinical antibiotics with many being multi-drug resistant. In addition, samples collected on the same day, from different surfaces had similar microbial fingerprints and patterns of antibiotic sensitivity.

\section{Conclusion}

Appropriate cleaning of surfaces decreased the amount of contamination and could ultimately play a role in decreasing the spread of infection. Moreover, from the microbial fingerprint and antibiotic sensitivity we suggest that hand contact with the surfaces initiates' microbial transmission. Thus strict compliance of $\mathrm{HCW}$ activities with infection control procedures is vital to reduce the risk of cross infection from surfaces to susceptible patients.

\section{Disclosure of interest}

None declared.

\section{Author details}

${ }^{1}$ School of Molecular Medical Sciences, University of Nottingham,

Nottingham, UK. ${ }^{2}$ School of Nursing, Midwifery and Physiotherapy, University of Nottingham, Nottingham, UK.

Published: 20 June 2013

'School of Molecular Medical Sciences, University of Nottingham, Nottingham, UK

Full list of author information is available at the end of the article

doi:10.1186/2047-2994-2-S1-P373

Cite this article as: Lary et al:: P373: Contamination and cross

contamination on hospital surfaces (near touch site). Antimicrobial

Resistance and Infection Control 2013 2(Suppl 1):P373. (c) 2013 Lary et al; licensee BioMed Central Ltd. This is an Open Access article distributed under the terms of the Creative Commons Attribution License (http://creativecommons.org/licenses/by/2.0), which permits unrestricted use, distribution, and reproduction in any medium, provided the original work is properly cited. 